\title{
Preliminary Investigation on the Chemical Constituents and Antioxidant Activities of Two Phellinus Mushrooms Collected in Foshan
}

\author{
Feng Zhu ${ }^{1 *}$, Weihong Lu ${ }^{2}$, Weijie Feng ${ }^{1}$, Zhaofeng Song ${ }^{1}$, Chunyan Wang1, Xin Chen ${ }^{1}$ \\ ${ }^{1}$ Department of Chemical Engineering, Foshan University, Foshan, China \\ ${ }^{2}$ School of Life Science and Engineering, Foshan University, Foshan, China \\ Email: *zhufeng@fosu.edu.cn
}

How to cite this paper: Zhu, F., Lu, W.H., Feng, W.J., Song, Z.F., Wang, C.Y. and Chen, X. (2017) Preliminary Investigation on the Chemical Constituents and Antioxidant Activities of Two Phellinus Mushrooms Collected in Foshan. International Journal of Organic Chemistry, 7, 25-33. https://doi.org/10.4236/ijoc.2017.71003

Received: October 6, 2016

Accepted: January 22, 2017

Published: January 25, 2017

Copyright $\odot 2017$ by authors and Scientific Research Publishing Inc. This work is licensed under the Creative Commons Attribution International License (CC BY 4.0).

http://creativecommons.org/licenses/by/4.0/

\begin{abstract}
The Phellinus mushrooms have been known for its immunomodulatory, hypolipidemic, and anticancer activities. In the current work, the chemical constituents of two Phellinus mushrooms, Phellinus pini 141016\# and Phellinus sp. 150802\#, which were collected in Foshan city, Guangdong province, were investigated preliminarily by pre-test tube method and by comparison with the known natural compounds from Phellinus pini, and their antioxidant activities were evaluated by the biochemical assay of hydroxyl and 2,2-diphenyl1-pricylhydrazyl (DPPH) radicals scavenging activity in vitro. The results show that both the two Phellinus mushrooms contain phenolics, alkaloids, lactones, steroids and terpenoids, and have potent antioxidant activities. The $\mathrm{IC}_{50}$ values of DPPH radicals and hydroxyl radicals for Phellinus pini 141016\# were $74.37 \mu \mathrm{g} / \mathrm{mL}$ and $59.69 \mu \mathrm{g} / \mathrm{mL}$, respectively, and the IC $_{50}$ values of DPPH radicals and hydroxyl radicals for Phellinus sp. 150802\# were $98.95 \mu \mathrm{g} / \mathrm{mL}$ and $165.47 \mu \mathrm{g} / \mathrm{mL}$, respectively. They are comparable to the antioxidant activity of the standard antioxidant ascorbic acid.
\end{abstract}

\section{Keywords}

Mushroom, Phellinus sp., Phellinus pini, Chemical Constituent, Antioxidant Activity

\section{Introduction}

Edible and medicinal mushrooms are an important source of natural antioxidants [1]. They are ubiquitous in nature and produce various classes of biologically active primary and secondary metabolites. Mushrooms in the genus Phellinus have attracted much attention due to its long history and high medicinal 
value [2]. Among them, Phellinus pini, also known as Huang Zhi, pine white rot fungus, which has anti-cancer, can enhance immunity, lower blood sugar and other activities, is a good medicine for cancer treatment [3] [4] [5]. During an ongoing study to discover natural products with antioxidant activity from mushrooms, we collected two mushrooms in Foshan city, Guangdong province, and identified them as Phellinus mushrooms. It was known that the chemical constituents isolated from the fungi of the genus Phellinus are steroids, terpenoids, polysaccharides and fatty acids. In addition, flavonoids and flavanone derivatives, enzymes, pyrone pigments, and alkaloids were also found in the genus of Phellinus [4] [6]. But to our best knowledge, the Phellinus mushrooms in Foshan had not yet been studied. Herein we report the preliminary investigation on the chemical constituents and antioxidant activities of the two Phellinus mushrooms. The aim of the study was to provide theoretical basis for the development and efficient utilization of them.

\section{Materials and Methods}

\subsection{Chemistry}

Analytical grade chemicals and reagents were directly used to perform various experiments.

\subsection{Analytical}

UV-2501 PC absorption spectrometer was used to measure the absorbance values.

\subsection{Mushrooms}

The No. 141016\# wild fruiting bodies (Figure 1) identified as Phellinus pini were collected in October in 2014 from Leigang Mountain in Foshan city, Guangdong Provice, China. The No. 150802\# wild fruiting bodies (Figure 2) were collected in August in 2015 from Leigang Mountain in Foshan City, Guangdong Province, China, and were identified as Phellinus sp., and it maybe is a novel specie of the genus of Phellinus.

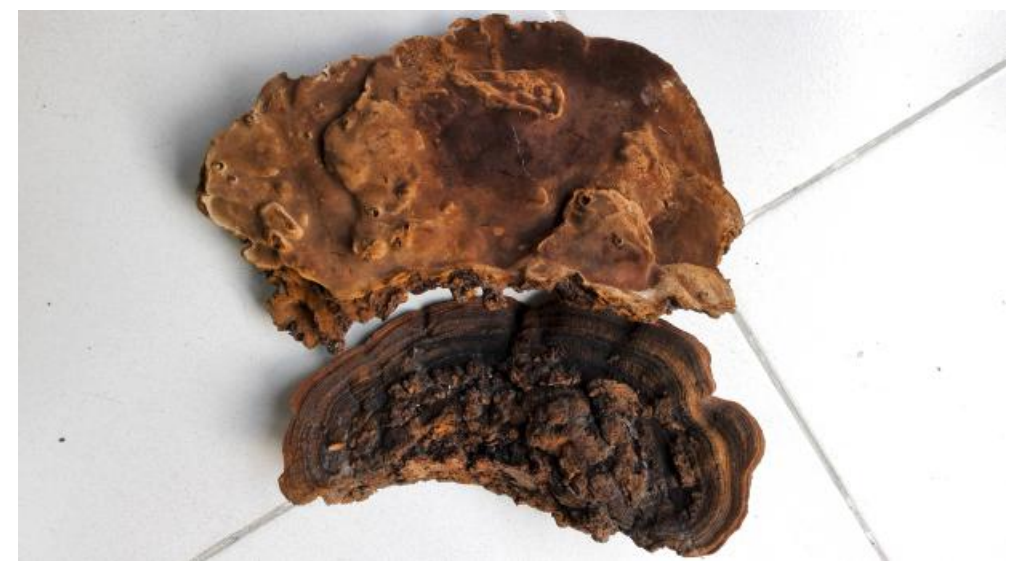

Figure 1. The mushroom of Phellinus pini 141016\#. 


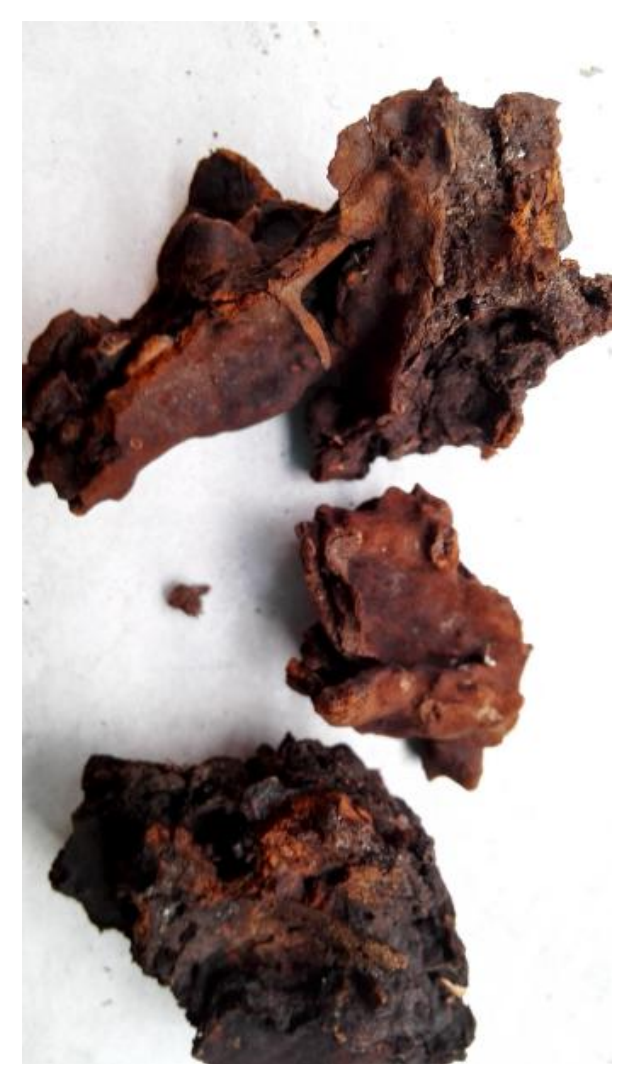

Figure 2. The mushroom of Phellinus sp. 150802\#.

\subsection{Preparation of the Crude Extracts}

The fresh fruiting bodies of the two Phellinus mushrooms were dried by air, and grinded into powder. The crude powders were extracted continuously with methanol for 24 hrs. The methanol extracts were combined and the methanol was recovered by vacuum rotary evaporation to obtain the crude extracts. A $1.23 \mathrm{~g}$ of crude extracts was obtained from $73 \mathrm{~g}$ of crude powders of the fruiting bodies of Phellinus pini 141016\#, yielding $1.68 \%$, and a $1.00 \mathrm{~g}$ of crude extracts was obtained from $56 \mathrm{~g}$ of crude powders of the fruiting bodies of Phellinus sp. 150802\#, yielding $1.79 \%$. All the crude extracts were solved in methanol and prepared into sample solutions in methanol with concentration of $5 \mathrm{mg} / \mathrm{mL}$.

\subsection{Preliminary Test on the Chemical Constituents in the Methanol Crude Extracts}

The chemical constituents of the methanol crude extracts were determined by preliminary-test tube method [7] [8]. The ferric chloride reagent was used to check the phenolic components. Alkaloids were detected by Dragendorff reagent. The hydrochloric acid-zinc powder test was used to check the flavonoids. The anthraquinones were examined by Bornträger reaction and magnesium acetate test. Cardiac glycosides were examined by Kedde reagent. The lactone and coumarin components were examined by the ferric hydroxamate reaction. The sterols and triterpenoids were examined by Liebermann-Burchard reaction and Salkowski reaction. 


\subsection{Antioxidant Activity Assay}

\section{Scavenging Activity on Hydroxyl Radical}

The hydroxyl radicals scavenging activity of the crude extracts were evaluated by salicylic acid- $\mathrm{FeSO}_{4}-\mathrm{H}_{2} \mathrm{O}_{2}$ method [8]. Spectrophotometric method was used to determine the hydroxyl radicals scavenging ability of different concentrations of sample solution in vitro. A $0-1.2 \mathrm{~mL}$ of sample solution in methanol was added to a clean plug tube, then methanol was added to make up the volume to 5 $\mathrm{mL}$, then $1 \mathrm{~mL}$ of $6 \mathrm{~mol} / \mathrm{L}$ salicylic acid solution in methanol was added. After shaking well, $1 \mathrm{~mL}$ of $2 \mathrm{~mol} / \mathrm{L}$ aqueous ferrous sulfate solution was added, then 1 $\mathrm{mL}$ of $1.5 \%$ aqueous hydrogen peroxide solution was added. Distilled water instead of $1.5 \%$ aqueous hydrogen peroxide solution is as a blank control. After shaking well, methanol was added until reaching the constant volume of $10 \mathrm{~mL}$. Finally, the tubes were placed in $37^{\circ} \mathrm{C}$ bath for $60 \mathrm{~min}$. The absorbance values were measured at $\lambda_{\max } 510 \mathrm{~nm}$, and calculated as a percentage of radical scavenging activity (\%RSA) according to "Equation (1)". The experiment was repeated three times. The \%RSA values were converted to activity of inhibition concentration at 50 percent $\left(\mathrm{IC}_{50}\right)$ using a graph plotted between \%RSA and the concentration. The standard antioxidant ascorbic acid was used in this experiment.

$$
\% R S A=\left[\left(A_{0}-A_{S}\right) \div A_{0}\right] \times 100
$$

$A_{0}$ is the absorbance value of salicylic acid- $\mathrm{FeSO}_{4}-\mathrm{H}_{2} \mathrm{O}_{2}$ system, and $A_{s}$ is the aborsance value of sample-salicylic acid- $\mathrm{FeSO}_{4}-\mathrm{H}_{2} \mathrm{O}_{2}$ system.

\section{Scavenging Activity on DPPH Radical}

The DPPH radical scavenging activity of the crude extracts was measured using the method of Seephonkai [2] and Wu [8]. Spectrophotometric method was used to determine the DPPH radicals scanvenging ability of different concentrations of sample solution in vitro. A $1 \mathrm{~mL}$ of different concentrations of the sample solution in methanol was mixed with $2 \mathrm{~mL}$ of $0.2 \mathrm{mmol} / \mathrm{L}$ DPPH solution in methanol. After $30 \mathrm{~min}$ at room temperature, the absorbance values of the sample were measured at $\lambda_{\max } 517 \mathrm{~nm}$ and calculated as a percentage of radical scavenging activity (\%RSA) according "Equation (2)". The \%RSA values were converted to activity of inhibition concentration at 50 percent $\left(\mathrm{IC}_{50}\right)$ using a graph plotted between \%RSA and the concentration. Standard antioxidant ascorbic acid was used in this experiment.

$$
\% R S A=\left[\left(A_{D P P H}-A_{s}\right) \div A_{D P P H}\right] \times 100
$$

$A_{D P P H}$ is the absorbance value of $1 \mathrm{~mL}$ of methanol mixed with $2 \mathrm{~mL}$ of 0.2 $\mathrm{mmol} / \mathrm{L} \mathrm{DPPH}$ solution in methanol, and $\mathrm{A}_{\mathrm{s}}$ is the absorbance value of $1 \mathrm{~mL}$ of sample solution in methanol mixed with $2 \mathrm{~mL}$ of $0.2 \mathrm{mmol} / \mathrm{L}$ DPPH solution in methanol.

\section{Results and Discussion}

\subsection{Chemical Constituents Preliminary Analysis}

To date, at least fourteen natural compounds 1-14 (Figure 3) had been found in 
<smiles>C=C(CC(CCc1ccccc1)c1ccccc1)c1ccccc1</smiles>

(5)

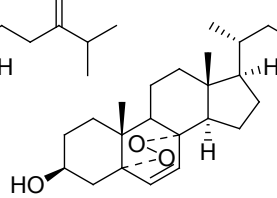

(2)<smiles>CCC(=O)/C=C/C=C/C(C)=C/C=C/C=C/c1ccccc1</smiles>

(7)<smiles>C=Cc1cc(O)c(O)cc1-c1c(O)cc(CCc2ccc(O)c(O)c2)oc1=O</smiles><smiles>C=Cc1ccc(O)cc1</smiles>

(8)

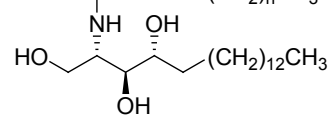

3) $n=24 ;(4) n=25$<smiles>C=Cc1ccc(O)cc1O</smiles>

(9)

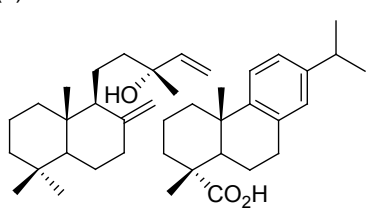

(14)

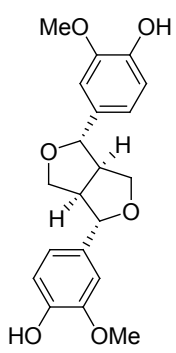

(10)

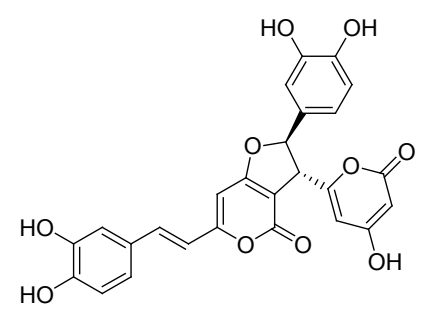

(11)
(13)

Figure 3. The known natural compounds from Phellinus pini.

Phellinus pini. In 1996, Lourenco et al. [9] reported that the steroids episteryl acetate (1) and ergosterol peroxide (2) and the lignan (+)-pinoresinol (10) had been isolated from the wild fruiting bodies of the fungus Phellinus pini. In addition, two new ceramides , N-(2'-hydroxynonacosanoyl)-D-erythro-1, 3, 4-trihydroxy-2-aminooctadecane (3) and N-(2'-hydroxytriacontanoyl)-D-erythro-1, 3, 4-trihydroxy-2-aminooctadecane (4), also had been obtained from the same source. At the same year, Ayer et al. [10] reported that five compounds, 2, 4, 6triphenylhex-1-ene (5), 2-farnesyl-5-methylbenzoquinone (6), 8-methyl-13phenyltrideca-4, 6, 8, 10, 12-pentaene-3-one (7), 4-vinylphenol (8) and 4-vinylresorcinol (9) had been isolated from the cultured mycelium of the fungus Phellinus pini, and all the five compounds showed activity against most fungi examined. In 2007, two phenylpropanoid-derived polyketides, hypholomine B (11) and pinillidine (12), with potent xanthine oxidase inhibitory activities were isolated from the cultured mycelium of Phellinus pini by bioassay-guided isolation by Wangun et al. [11]. Recently, two diterpinoids [12], 8, 14-labdadien-13-ol (13) and dehydroabietic acid (14), were isolated from the fruit body of Phellinus pini, they could inhibit NO production in LPS-activated RAW 264.7 cells. In addition, many scholars [13] [14] also studied the polysaccharides of Phellinus pini and its biological activities.

In this work, the sample solution of the methanol crude extracts from Phellinus pini 141016 \# showed a blue-violet color reaction with ferric chloride, suggesting the presence of phenolic components. The sample solution evaporated in water bath to get the residue, the residue was dissolved in $5 \%$ sulfuric acid, then filtration, the filtrate reacted with Dragendorff reagents to produce red precipi- 
tate, indicating that the sample contains alkaloids. The sample solution in the hydrochloric acid-zinc powder test did not occur color reaction, indicating that the sample does not contain flavonoids. In the Bornträger test, the sample solution produced a red reaction with $10 \%$ sodium hydroxide, but the red color faded when heating after adding a small amount of $30 \%$ hydrogen peroxide solution. Additionally, the sample solution did not occur color reaction with $1 \%$ magnesium acetate. All these phenomena suggest that there is no anthraquinone ingredient in the sample. The sample solution did not occur color reaction with Kedde reagent, indicating that no cardiac glycosides in the sample. In the ferric hydroxamate test, the sample solution showed red reaction, indicating the presence of lactones. The sample solution produced a remarkable color reaction in the Liebermann-Burchard reaction and the Salkowski reaction, indicating the presence of sterols and triterpenes.

The experimental results show that Phellinus pini 141016 \# contain phenolics, alkaloids, lactones, steroids and terpenoids, which were consistent with the types of the known natural compounds of Phellinus pini (Figure 3). Since the sample solution of the methanol crude extracts from Phellinus sp. 150802\# showed the same reaction phenomena as the methanol crude extracts from Phellinus pini 141016\# in the chemical constituents preliminary test, it was concluded that Phellinus pini 141016\# also contain phenolics, alkaloids, lactones, steroids and terpenoids.

\subsection{Antioxidant Activity}

The Phellinus mushrooms are an important group of medicinal fungi. Cao et al. [15] found all the extracts from fruiting bodies of Phellinus mori, P. baumii and $P$. vaninii had in vitro antioxidant activities. Seephonkai et al. [2] investigated the antioxidant activity and total phenolic content from the crude extracts and crude fractions of ten species of Phellinus mushrooms collected from northeast Thailand, and the experimental results showed that some of the investigated extracts exhibited potent radical scavenging activity, while the samples with potent antioxidant activity were also determined to have high amount of total phenolics. Wang et al. [16] studied on preparation and detection antioxidant capacities of three polysaccharides, water-extracted polysaccharides (PSI), alkali-extracted polysaccharides (PSII) and sulfate polysaccharides (PSIII), from the fruiting bodies of Phellinus pini, and found PSII and PSIII showed the better result of antioxidant activities with concentration dependence. They [17] also studied the effects of the three polysaccharidies on antioxidant capacity of normal mice, and the results showed that the three polysaccharides significantly enhanced antioxidant capacity in mice, but also increased oxidative stress in vivo. Yang et al. [18] obtained a polysaccharide designated as PP60-S1 from the fruiting bodies of Phellinus pini, and found PP60-S1 showed a potent antioxidant activity in vitro. Two heteropolysaccharides, PPM and PPE, were isolated from mycelium and culture medium of Phellinus pini, respectively, and Jiang et al. [19] found PPM possessed better antioxidant activity in vitro than PPE. 
In this work, the antioxidant activities of the methanol extracts from the wild fruiting bodies of Phellinus pini 141016 \# and Phellinus sp. 150802\# were evaluated by free radical scavenging test. The results are shown in Figure 4 and Figure 5. The results showed that the two species had significant antioxidant activities, and the free radicals scavenging activity increased with the increase of the concentration of the samples. The $\mathrm{IC}_{50}$ values of DPPH radicals and hydroxyl radicals for Phellinus pini 141016\# were $74.37 \mu \mathrm{g} / \mathrm{mL}$ and $59.69 \mu \mathrm{g} / \mathrm{mL}$, respectively. And the $\mathrm{IC}_{50}$ values of DPPH radicals and hydroxyl radicals for Phellinus sp. $150802 \#$ were $98.95 \mu \mathrm{g} / \mathrm{mL}$ and $165.47 \mu \mathrm{g} / \mathrm{mL}$, respectively. They are comparable to the antioxidant activity of the standard antioxidant ascorbic acid, which $\mathrm{IC}_{50}$ values of DPPH radicals and hydroxyl radicals were $66.01 \mu \mathrm{g} / \mathrm{mL}$ and 103.34 $\mu \mathrm{g} / \mathrm{mL}$, respectively.

\section{Conclusions}

The chemical constituents preliminary test results show that both the methanol extracts from the wild fruiting bodies of Phellinus pini 141016\# and Phellinus sp. 150802\# contain phenolics, alkaloids, lactones, steroids and terpenoids which were consistent with the types of the known natural compounds of Phellinus pini.

Free radicals scavenging activity experimental results show that both the methanol extracts from the wild fruiting bodies of Phellinus pini 141016\# and Phellinus sp. 150802\# have potent antioxidant activities, and the free radicals scavenging activity has increased with the increase of the concentration of the samples. They are comparable to the antioxidant activity of the standard antioxidant ascorbic acid.

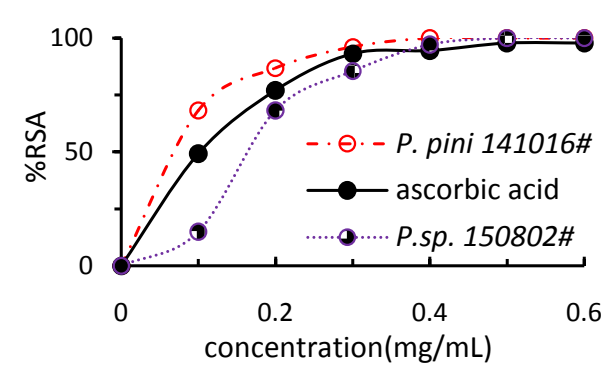

Figure 4. Hydroxyl radicals scavenging activity of Phellinus pini 141016\# and Phellinus sp. 150802\#.

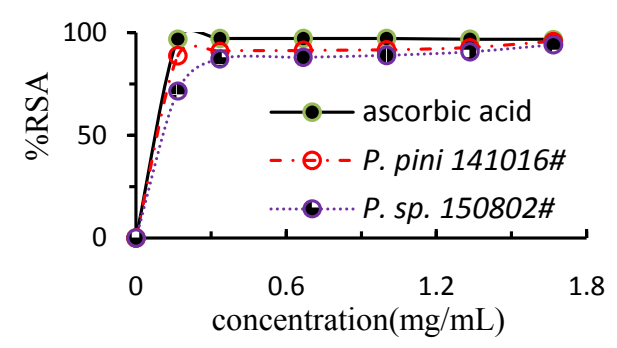

Figure 5. DPPH radicals scavenging activity of Phellinus pini 141016\# and Phellinus sp. 150802\#. 
In conclusion, the results of the present study indicate that the mushrooms Phellinus pini 141016\# and Phellinus sp. 150802\# collected in Foshan have a great potential to be a good source of natural radical scavenger to be used in the food and pharmaceutical industries. Its antioxidant activities could be related to other biological activities for its use in traditional medicine. The next work is to isolate and purify natural compounds from these two species, and to evaluate their antioxidant activities in vitro and in vivo, finally to explore the two Phellinus mushrooms as novel antioxidants in functional foods and medicine.

\section{References}

[1] Kozarski, M., Klaus, A., Jakovljevic, D., Todorovic, N., Vunduk, J., Petrovic, P., Niksic, M., Vrvic, M.M. and van Griensven, L. (2015) Antioxidants of Edible Mushrooms. Molecules, 20, 19489-19525. https://doi.org/10.3390/molecules201019489

[2] Seephonkai, P., Samchai, S., Thongsom, A., Sunaart, S., Kiemsanmuang, B. and Chakuton, K. (2011) DPPH Radical Scavenging Activity and Total Phenolics of Phellinus Mushroom Extracts Collected from Northeast of Thailand. Chinese Journal of Natural Medicines, 9, 441-445.

[3] Qi, Y.D., Wu, M.Y. and Shen, R. (2015) Research Advance of Phellinus pini. Forest By-Product and Speciality in China, No. 6, 83-85.

[4] Du, L.M., Han, R., An, T.C., Shang, X.F. and Wang, J.S. (2014) Resource and Effect of Medical Fungi Phellinus pini (Fr.) Quél. in Shanxi Province. Modern Agricultural Science \& Technology, No. 7, 119-120.

[5] Dai, Y.C. and Yang, Z.L. (2008) A Revised Checklist of Medicinal Fungi in China. Mycosystema, 27, 801-824.

[6] Xue, M. and Wang, Q.Y. (2004) Chemical Constituents and Biological Activities of the Phellinus Mushroom. World Phytomedicines, 19, 103-105.

[7] Xu, S.Y., Jin, M.H., Zhao, L.Y., Li, J.J., Wei, Y., Jiang, Z.F., Luo, Q. and Chen, X.H. (2014) Study on the Chemical Components and Acute Toxicological Evaluation of Wild Russula sp. from Meixian County, Guangdong Province. Food Research and Development, 35, 24-26.

[8] Wu, J.S. and Zhu, F. (2016) Chemical Constituents Pre-Analysis and Antioxidant Activity of the Puffball Calvatia candida from Foshan. Journal of Organic Chemistry Research, 4, 69-76. https://doi.org/10.12677/JOCR.2016.43010

[9] Lourenco, A., Lobo, A.M., Rodriguez, B. and Jimeno, M.L. (1996) Ceramides from the Fungus Phellinus pini. Phytochemistry, 43, 617-620.

https://doi.org/10.1016/0031-9422(96)00335-4

[10] Ayer, W.A., Muir, D.J. and Chakravarty, P. (1996) Phenolic and Other Metabolites of Phellinus pini, a Fungus Pathogenic to Pine. Phytochemistry, 42, 1321-1324. https://doi.org/10.1016/0031-9422(96)00125-2

[11] Wangun, H.V.K. and Hertweck, C. (2007) Squarrosidine and Pinillidine: 3,3'-Fused Bis(Styrylpyrones) from Pholiota squarrosa and Phellinus pini. European Journal of Organic Chemistry, 2007, 3292-3295. https://doi.org/10.1002/ejoc.200700090

[12] Jang, H.J. and Yang, K.S. (2011) Inhibition of Nitric Oxide Production in RAW 264.7 Macrophages by Diterpenoids from Phellinus pini. Archives of Pharmacal Research, 34, 913-917. https://doi.org/10.1007/s12272-011-0608-Z

[13] Pei, L.J., Yuan, L., Ma, J.N. and Ni, X.Z. (2010) The Study of Structure and Immunobiological Activity of the Polysaccharide from the Mycelium of Phellinus pini. Journal of Molecular Science, 26, 103-107. 
[14] Yuan, L., Zhong, G.H. and Tian, F.Y. (2010) Study on Composition and Immunomodulating Activities of Extracellular Polysaccharide from Culture Medium of Phellinus pini. The Chinese Journal of Modern Applied Pharmacy, No. 8, 711-714.

[15] Cao, C.L., Han, M.L. Cui, B.K. and Yu, H.Y. (2013) Antioxidant Activities of Different Fractional Extracts from Fruiting Bodies of Three Phellinus Species. Mycosystema, 32, 883-890.

[16] Wang, W.H., Li, Y. and Liu, A.J. (2006) Preparation and Antioxidant Activities of Different Polysaccharides from the Fruit Body of Phellinus pini. Food Research and Development, 27, 53-56.

[17] Wang, W.H., Li, Y. and Liu, A.J. (2008) Effect of Different Polysaccharides from Fungus Phellinus pini on Antioxidant Capacity of Normal Mice. Progress in Modern Biomedicine, 8, 1439-1441.

[18] Yang, K., Jin, Y.Z., Xing, C., Hu, J.N., Wang, R.W. and Sun, P.L. (2014) Study on Isolation, Structural Characterization and Antioxidant Activity Evaluation of Polysaccharide PP60-S1 from Phellinus pini. Science and Technology of Food Industry, $35,76-81$.

[19] Jiang, P., Yuan, L., Cai, D., Jiao, L. and Zhang, L. (2015) Characterization and Antioxidant Activities of the Polysaccharides from Mycelium of Phellinus pini and Culture Medium. Carbohydrate Polymers, 117, 600-604.

https://doi.org/10.1016/j.carbpol.2014.10.013

\section{Scientific Research Publishing}

\section{Submit or recommend next manuscript to SCIRP and we will provide best} service for you:

Accepting pre-submission inquiries through Email, Facebook, LinkedIn, Twitter, etc. A wide selection of journals (inclusive of 9 subjects, more than 200 journals) Providing 24-hour high-quality service User-friendly online submission system Fair and swift peer-review system Efficient typesetting and proofreading procedure Display of the result of downloads and visits, as well as the number of cited articles Maximum dissemination of your research work

Submit your manuscript at: http://papersubmission.scirp.org/ Or contact ijoc@scirp.org 